\title{
Outcomes of Cardiac Contractility Modulation: A Systematic Review and Meta-Analysis of Randomized Clinical Trials
}

\author{
Ramy Mando (D), ${ }^{1}$ Akshay Goel, ${ }^{2}$ Fuad Habash $\left(\mathbb{D},{ }^{2}\right.$ Marwan Saad, ${ }^{2}$ Karam Ayoub, ${ }^{3}$ \\ Srikanth Vallurupalli, ${ }^{2}$ and Waddah Maskoun $\mathbb{1}^{4}$ \\ ${ }^{1}$ Department of Internal Medicine, Beaumont Health System, Royal Oak, MI, USA \\ ${ }^{2}$ Department of Cardiovascular Medicine, University of Arkansas for Medical Sciences, USA \\ ${ }^{3}$ Department of Cardiovascular Medicine, University of Kentucky, Lexington, KY, USA \\ ${ }^{4}$ Department of Cardiovascular Medicine, Henry Ford Hospital, Detroit, MI, USA
}

Correspondence should be addressed to Waddah Maskoun; wmaskoul@hfhs.org

Received 25 February 2019; Accepted 19 May 2019; Published 17 June 2019

Academic Editor: Hangang Yu

Copyright (C) 2019 Ramy Mando et al. This is an open access article distributed under the Creative Commons Attribution License, which permits unrestricted use, distribution, and reproduction in any medium, provided the original work is properly cited.

\begin{abstract}
Background. Cardiac contractility modulation (CCM) is a device therapy for systolic heart failure (HF) in patients with narrow QRS. We aimed to perform an updated meta-analysis of the randomized clinical trials (RCTs) to assess the efficacy and safety of CCM therapy. Methods. We conducted a systematic review and meta-analysis of randomized clinical trials (RCTs) between January 2001 and June 2018. Outcomes of interest were peak oxygen consumption (peak VO2), 6-Minute Walk Distance (6MWD), Minnesota Living with Heart Failure Questionnaire (MLHFQ), HF hospitalizations, cardiac arrhythmias, pacemaker/ICD malfunctioning, all-cause hospitalizations, and mortality. Data were expressed as standardized mean difference (SMD) or odds ratio (OR). Results. Four RCTs including 801 patients $(\mathrm{CCM} \mathrm{n}=394)$ were available for analysis. The mean age was $59.63 \pm 0.84$ years, mean ejection fraction was $29.14 \pm 1.22 \%$, and mean QRS duration was $106.23 \pm 1.65$ msec. Mean follow-up duration was six months. CCM was associated with improved MLWHFQ (SMD -0.69, $\mathrm{p}=0.0008)$. There were no differences in HF hospitalizations $(\mathrm{OR} 0.76, \mathrm{p}=0.12)$, 6MWD (SMD 0.67, p = 0.10), arrhythmias (OR 1.40, $\mathrm{p}=0.14)$, pacemaker/ICD malfunction/sensing defect $(\mathrm{OR} 2.23, \mathrm{p}=0.06)$, all-cause hospitalizations (OR 0.73, $\mathrm{p}=0.33$ ), or all-cause mortality (OR 1.04, $\mathrm{p}=0.92$ ) between the CCM and non-CCM groups. Conclusions. Short-term treatment with CCM may improve MLFHQ without significant difference in 6MWD, arrhythmic events, HF hospitalizations, all-cause hospitalizations, and all-cause mortality. There is a trend towards increased pacemaker/ICD device malfunction. Larger RCTs might be needed to determine if the CCM therapy will be beneficial with longer follow-up.
\end{abstract}

\section{Introduction}

Current treatment options for patients with systolic heart failure (HF) target improving survival, quality of life, left ventricular (LV) function, and reducing HF-related hospitalizations. Therapy typically includes optimization of medical management, revascularization, managing valvular heart disease, and device therapy when appropriate (defibrillator and biventricular pacing).

Several studies have shown that cardiac resynchronization therapy (CRT) helps patients with wide QRS on 12 Lead ECG (>120 msec), an ejection fraction $(\mathrm{EF}) \leq 35 \%$, and New York Heart Association (NYHA) class II-IV symptoms [1-3]. Approximately $30 \%$ of those who meet the aforementioned criteria do not experience improvement with CRT. Moreover, about $50 \%$ of individuals with advanced HF do not meet criteria and are therefore not candidates for CRT [2, 46]. This creates a cohort of patients including those with advanced $\mathrm{HF}$ and a narrow QRS complex $(<120 \mathrm{msec})$ and nonresponders to CRT requiring new therapies to improve their overall quality of life.

Cardiac contractility modulation (CCM) is a modality that delivers a high voltage impulse to the right ventricular septum 30-40 msec after activation of cardiomyocytes during the absolute refractory period. In theory, this improves calcium handling and increases ventricular contractility with resultant improvement in exercise tolerance and functional capacity [7-9]. It is not clear if CCM may play a role 
in patients who are not good candidates for CRT devices (narrow QRS), nonresponders to CRT or in conjunction with CRT device therapy $[10,11]$. Previous studies of CCM were small and likely underpowered to detect significant differences $[12,13]$. With the publication of the recent FIX-HF$5 \mathrm{C}$ study, we performed a meta-analysis of the randomized clinical trials (RCTs) to assess the efficacy and safety of CCM therapy in patients with systolic HF and narrow QRS complex.

\section{Methods}

2.1. Search Strategy, Study Selection, and Data Extraction. A systematic review of PubMed, MEDLINE, and Cochrane Central Register of Controlled Trials was preformed from 2001 until June 2018 without any language restriction, according to the Preferred Reporting Items for Systematic Reviews and Meta-Analyses (PRISMA) guidelines [14]. We used the keywords "cardiac contractility modulation", "heart failure", and "systolic heart failure". After eligible studies were retrieved, we screened their bibliographies for any potential missed studies through the initial search. Furthermore, prior meta-analyses were screened to ensure the inclusion of all eligible studies. Studies available for inclusion were (1) RCTs assessing safety, efficacy and outcomes of cardiac contractility modulation, (2) adult patients ( $\geq 18$ years), (3) intervention group assigned to CCM, and (4) control group assigned to optimal medical therapy (OMT). Two independent authors extracted data on study characteristics, patient demographics, and quality assessments. Extracted data were revised by a third author to ensure accuracy. Discrepancies were resolved by consensus among authors. Study level data were extracted since individual subject data were not available.

2.2. Outcome Measures. Primary outcomes were (1) allcause mortality, (2) all-cause hospitalizations, (3) worsening heart failure/hospitalizations, (4) incidence of cardiac arrhythmias defined as symptomatic supraventricular or ventricular arrhythmia and/or requiring intervention, and (5) pacemaker/ICD malfunctioning/missensing. Other heart failure outcomes of interest were (6) peak oxygen consumption (peak $\mathrm{VO}_{2}, \mathrm{~mL} / \mathrm{kg} / \mathrm{min}$ ) assessed by cardiopulmonary exercise testing, an important objective prognostic measure of peak aerobic capacity [15-17]; this is important to help differentiate true results from placebo effect, particularly in nonsham-controlled studies; (7) six-minute walk distance (6MWD) which is the distance covered, in meters, over 6 minutes of maximal self-paced walking [18]; (8) Minnesota Living with Heart Failure Questionnaire (MLHFQ) used to assess patient's perception of the consequences of HF on the physical, socioeconomic, and psychological aspects of life [19].

2.3. Assessment of Quality and Bias. The quality of the included trials and the risk of the bias were assessed by two independent reviewers using the components recommended by Cochrane Collaboration, including random sequence generation, allocation concealment, blinding of participants

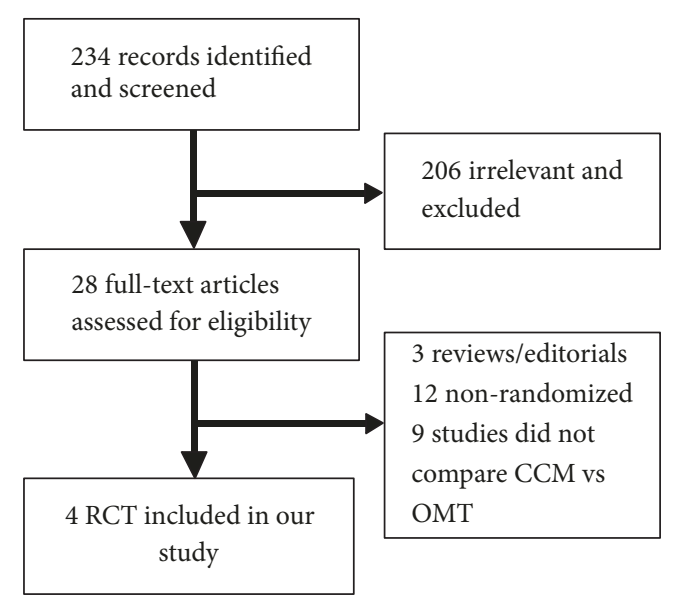

Figure 1: A flow diagram of the search strategy conducted. A flow diagram of the search strategy conducted. The purpose of this figure is to provide a graphical representation of the manner in which we conducted our search for RCT for CCM. PRISMA guidelines were followed.

and personnel, blinding of outcome assessment, incomplete outcome data, selective reporting, and other sources of bias. Trials were considered low risk for bias if having $<2$ highrisk components and high potential for bias if having $>4$ high-risk components. The overall quality of evidence for each outcome was further assessed using GRADE (Grades of Recommendation, Assessment, Development and Evaluation) tool recommended by the Cochrane Handbook for Systematic Reviews of Intervention.

2.4. Statistical Analysis. Descriptive analyses were performed using weighted means and standard deviations (SD) for continuous variables and weighted frequencies for categorical variables. Random effect DerSimonian-Laird model was used to calculate standardized mean difference (SMD) for the continuous variable outcomes and odds ratio (OR) to estimate the effect sizes for other outcomes. Heterogeneity between the studies of each outcome was evaluated as well.

The sample size of each study was used as its weight. P-values (2-tailed) were considered statistically significant if less than 0.05 . We calculated the confidence intervals (CIs) at the 95\% level for the overall estimates effect. All statistical analyses were conducted using Revman 5.3. The Nordic Cochrane Centre, Copenhagen, Denmark, was used to conduct meta-analysis for outcome measures [22].

\section{Results}

3.1. Identified Studies. Four RCTs including a total of 801 patients (394 patients with CCM) met our eligibility criteria $[12,13,20,21]$ (Figure 1). Mean age was $59.63 \pm 0.84$ years, $75.28 \%$ were males, and $63.67 \%$ had ischemic cardiomyopathy with mean ejection fraction $29.14 \pm 1.22 \%$ and mean QRS duration of $106.23 \pm 1.65 \mathrm{msec}$. Details about the trials' characteristics and patients' baseline demographics are summarized in Table 1 . Baseline characteristics in these 
TABLE 1: Studies characteristics and patient demographics.

\begin{tabular}{|c|c|c|c|c|}
\hline & $\begin{array}{l}\text { FIX-HF-5 Pilot } \\
{[12]}\end{array}$ & $\begin{array}{c}\text { FIX-CHF-4 } \\
{[13]} \\
\text { (Group 1/Group 2) }\end{array}$ & $\begin{array}{l}\text { FIX-HF-5 } \\
\quad[20]\end{array}$ & $\begin{array}{c}\text { FIX-HF-5C } \\
{[21]}\end{array}$ \\
\hline Year & 2006 & 2008 & 2011 & 2018 \\
\hline Sample Size $(N)$ & 49 & 164 & 428 & 160 \\
\hline Patients Withdrawn & 0 & $\begin{array}{l}5 \text { (group 1) } \\
4 \text { (group 2) }\end{array}$ & $\begin{array}{c}17(\mathrm{OMT}) \\
6(\mathrm{CCM}) \\
\end{array}$ & $\begin{array}{l}3(\mathrm{OMT}) \\
1(\mathrm{CCM})\end{array}$ \\
\hline Study Design & $\begin{array}{l}\text { CCM to all patients, } \\
25 \text { active CCM vs } 24 \\
\text { inactive CCM }\end{array}$ & $\begin{array}{c}\text { Crossover Study: } \\
\text { CCM to all patients; } \\
\text { Group } 1 \text { (N=80; CCM } \\
\text { first } 3 \text { months), Group } \\
2 \text { (N=84; sham first } 3 \\
\text { months) }\end{array}$ & $\begin{array}{l}\text { CCM Implant }(\mathrm{N}=215) \\
\text { vs OMT }(\mathrm{N}=213)\end{array}$ & $\begin{array}{l}\text { CCM Implant }(\mathrm{N}= \\
74) \text { vs OMT }(\mathrm{N}=86)\end{array}$ \\
\hline $\begin{array}{l}\text { Ejection Fraction } \\
\text { Inclusion Criteria }\end{array}$ & $<35 \%$ & $<35 \%$ & $\leq 35 \%$ & $\geq 25 \%$ and $\leq 45 \%$ \\
\hline Mean Follow up & 6 months & 6 months & $\begin{array}{c}6 \text { months (noninferiority } \\
\text { at } 12 \text { months) }\end{array}$ & 6 months \\
\hline Outcomes & $\begin{array}{l}\text { NYHA Class, 6MWD, } \\
\text { Stress Test, Holter } \\
\text { Monitoring }\end{array}$ & $\begin{array}{l}\text { Holter Monitoring. } \\
\text { Changes in peak } \mathrm{VO}_{2} \text {, } \\
\text { MLHFQ, and } 6 \mathrm{MWD} \\
\text { at the end of } 12 \text { and } 24 \\
\text { weeks. }\end{array}$ & $\begin{array}{c}\text { Ventilatory anaerobic } \\
\text { threshold, peak O2, } \\
\text { MLHFQ, non-inferiority } \\
\text { based on mortality and } \\
\text { hospitalization with } \\
12.5 \% \text { allowable delta (12 } \\
\text { months) }\end{array}$ & $\begin{array}{l}\text { Peak } \mathrm{VO}_{2}, \text { MLWHFQ, } \\
\text { NYHA Class, } 6 \mathrm{MWD} \text {, } \\
\text { safety assessed by } \\
\text { percentages of } \\
\text { patients free of } \\
\text { device-related events. }\end{array}$ \\
\hline Study Centers & $\begin{array}{c}\text { Single Center - Lone } \\
\text { Star Arrhythmia and } \\
\text { Heart Failure Center - } \\
\text { Texas } \\
\end{array}$ & $\begin{array}{l}\text { Single Center - } \\
\text { Germany }\end{array}$ & 50 US Centers & $\begin{array}{l}42 \text { Centers (US, } \\
\text { Germany, and } \\
\text { Czechia). }\end{array}$ \\
\hline Mean age (CCM/OMT) & $\begin{array}{c}52 \pm 15.0 \\
59.6 \pm 12.0 \\
\end{array}$ & $\begin{array}{c}58.9 \pm 9.8 \\
59.9 \pm 10 \\
\end{array}$ & $\begin{array}{l}58.09 \pm 12.79 \\
58.55 \pm 12.33 \\
\end{array}$ & $\begin{array}{l}63 \pm 11 \\
63 \pm 11\end{array}$ \\
\hline Male (CCM/OMT) & $68 \% / 71 \%$ & $88.8 \% / 81 \%$ & $73.5 \% / 70.9 \%$ & $73 \% / 79.1 \%$ \\
\hline $\begin{array}{l}\mathrm{SBP}(\mathrm{mmHg}) \\
(\mathrm{CCM} / \mathrm{OMT})\end{array}$ & $\begin{array}{c}118.6 \pm 19.7 \\
115 \pm 20.6 \\
\end{array}$ & $\begin{array}{c}114.7 \pm 17.0 \\
117.1 \pm 17.9 \\
\end{array}$ & $\begin{array}{c}116.65 \pm 19.48 \\
115.61 \pm 17.61 \\
\end{array}$ & $\begin{array}{l}123 \pm 18 \\
126 \pm 19 \\
\end{array}$ \\
\hline $\begin{array}{l}\text { QRS Duration (msec) } \\
\text { (CCM/OMT) }\end{array}$ & $\begin{array}{l}109.2 \pm 15.8 \\
101.3 \pm 14.2 \\
\end{array}$ & $\begin{array}{l}119.9 \pm 28.3 \\
116.3 \pm 26.6 \\
\end{array}$ & $\begin{array}{c}101.63 \pm 15.30 \\
101.51 \pm 12.81 \\
\end{array}$ & $\begin{array}{c}103 \pm 13.0 \\
103.6 \pm 12.1 \\
\end{array}$ \\
\hline $\begin{array}{l}\text { \% ICD/Pacemaker } \\
\text { (CCM/OMT) }\end{array}$ & $\begin{array}{l}88 \%(22) \\
83 \%(20) \\
\end{array}$ & $\begin{array}{l}68.3 \%(55) \\
59.4 \%(50) \\
\end{array}$ & $\begin{array}{l}96 \%(207 / 215) \\
95 \%(202 / 213) \\
\end{array}$ & $\begin{array}{l}87.8 \%(65 / 74) \\
84.9 \%(73 / 86) \\
\end{array}$ \\
\hline $\begin{array}{l}\text { 6MWD Baseline }(m) \\
(\mathrm{CCM} / \mathrm{OMT})\end{array}$ & $\begin{array}{c}321 \\
352 \pm 95.4 \\
\end{array}$ & $\begin{array}{l}386 \pm 103 \\
394 \pm 102 \\
\end{array}$ & $\begin{array}{l}326.38 \pm 82.10 \\
323.99 \pm 92.44 \\
\end{array}$ & $\begin{array}{c}317 \pm 88 \\
324 \pm 90 \\
\end{array}$ \\
\hline NYHA Class Included & III and IV & II and III & III and IV & III and IV \\
\hline $\begin{array}{l}\text { NYHA Class III } \\
(\mathrm{CCM} / \mathrm{OMT})\end{array}$ & $\begin{array}{c}100 \% \\
96 \% \\
\end{array}$ & $\begin{array}{c}72.5 \% \\
80 \% \\
\end{array}$ & $\begin{array}{l}91.16 \% \\
85.92 \% \\
\end{array}$ & $\begin{array}{l}86.5 \% \\
90.7 \% \\
\end{array}$ \\
\hline $\begin{array}{l}\text { Ischemic } \\
\text { Cardiomyopathy } \\
\text { (CCM/OMT) }\end{array}$ & $\begin{array}{l}64 \% \\
67 \%\end{array}$ & $\begin{array}{c}63.8 \% \\
56 \%\end{array}$ & $\begin{array}{l}64.7 \% \\
66.7 \%\end{array}$ & $\begin{array}{l}62.2 \% \\
59.3 \%\end{array}$ \\
\hline $\begin{array}{l}\text { Baseline LVEF (\%) } \\
\text { (CCM/OMT) }\end{array}$ & $\begin{array}{c}24.9 \pm 6.5 \\
31.4 \pm 7.4 \\
\end{array}$ & $\begin{array}{l}29.3 \pm 6.6 \\
29.8 \pm 7.8 \\
\end{array}$ & $\begin{array}{l}25.74 \pm 6.60 \\
26.09 \pm 6.54 \\
\end{array}$ & $\begin{array}{l}33 \pm 6 \\
33 \pm 5 \\
\end{array}$ \\
\hline $\begin{array}{l}\text { Ventilatory Anaerobic } \\
\text { Threshold (VAT) } \\
\text { (CCM/OMT) }\end{array}$ & $\begin{array}{l}10.6 \pm 2.4 \\
12.3 \pm 2.5\end{array}$ & Not documented & $\begin{array}{l}10.95 \pm 2.24 \\
10.97 \pm 2.18\end{array}$ & Not documented \\
\hline $\begin{array}{l}\text { Peak O2 Consumption } \\
\text { (CCM/OMT) }\end{array}$ & $\begin{array}{l}14.3 \pm 2.8 \\
16.0 \pm 2.9\end{array}$ & $\begin{array}{l}14.1 \pm 3.0 \\
13.6 \pm 2.7\end{array}$ & $\begin{array}{l}14.74 \pm 3.06 \\
14.71 \pm 2.92\end{array}$ & $\begin{array}{l}15.5 \pm 2.6 \\
15.4 \pm 2.8\end{array}$ \\
\hline
\end{tabular}

OMT: optimal medical therapy, CCM: cardiac contractility modulation, 6MWD: 6-minute walking distance, MLWHFQ: Minnesota Living with Heart Failure Questionnaire, SBP: systolic blood pressure, SD: standard deviation, LVEF: left ventricular ejection fraction, and VAT: ventilatory anaerobic thresholds. 
TABLE 2: A summary of reported adverse events and frequency.

\begin{tabular}{|c|c|c|c|c|c|c|c|c|}
\hline & \multicolumn{2}{|c|}{ FIX-HF-5 Pilot [12] } & \multicolumn{2}{|c|}{ FIX-CHF-4 [13] } & \multicolumn{2}{|c|}{ FIX-HF-5 [20] } & \multicolumn{2}{|c|}{ FIX-HF-5C [21] } \\
\hline & $\begin{array}{c}\text { CCM } \\
(\mathrm{N}=25)\end{array}$ & $\begin{array}{c}\text { OMT } \\
(\mathrm{N}=24)\end{array}$ & $\begin{array}{c}\text { CCM } \\
\text { ON }(N=160)\end{array}$ & $\begin{array}{c}\text { CCM } \\
\text { OFF }(N=161)\end{array}$ & $\begin{array}{c}\mathrm{CCM} \\
(\mathrm{N}=210)\end{array}$ & $\begin{array}{c}\text { OMT } \\
(\mathrm{N}=212)\end{array}$ & $\begin{array}{c}\text { CCM } \\
(\mathrm{N}=74)\end{array}$ & $\begin{array}{c}\text { OMT } \\
(\mathrm{N}=86)\end{array}$ \\
\hline $\begin{array}{l}\text { General } \\
\text { Cardiopulmonary } \\
\text { Event }\end{array}$ & 1 & 4 & 2 & 3 & 60 & 58 & 3 & 2 \\
\hline General Medical & 3 & 10 & 1 & 6 & 98 & 81 & 7 & 7 \\
\hline $\begin{array}{l}\text { Arrhythmia (VF, VT, } \\
\text { AF, SVT) }\end{array}$ & 1 & 2 & 6 & 4 & 40 & 30 & 3 & 2 \\
\hline Worsening HF & 2 & 3 & 7 & 8 & 72 & 85 & 3 & 7 \\
\hline $\begin{array}{l}\text { ICD/Pacemaker } \\
\text { malfunction or } \\
\text { Sensing Defect }\end{array}$ & 1 & 0 & $1 *$ & 0 & 13 & 7 & 2 & 0 \\
\hline Bleeding & NA & NA & NA & NA & 8 & 8 & 0 & 1 \\
\hline Sepsis & NA & NA & NA & NA & 11 & 2 & 1 & 1 \\
\hline Localized Infection & NA & NA & NA & NA & 33 & 36 & 1 & 4 \\
\hline $\begin{array}{l}\text { Neurologic } \\
\text { Dysfunction }\end{array}$ & NA & NA & NA & NA & 3 & 14 & 0 & 0 \\
\hline $\begin{array}{l}\text { Thromboembolism } \\
\text { (non-neurologic) }\end{array}$ & NA & NA & NA & NA & 3 & 5 & 1 & 1 \\
\hline $\begin{array}{l}\text { Optimizer } \\
\text { Malfunction }\end{array}$ & NA & NA & 1 & NA & 30 & NA & 6 & NA \\
\hline Total & 8 & 18 & 20 & 22 & 371 & 326 & 27 & 25 \\
\hline $\begin{array}{l}\text { Complications } \\
\text { Related to CCM } \\
\text { procedure/Device }\end{array}$ & $\begin{array}{r}2 \text { lead dis } \\
\text { One eve } \\
\text { sensatio } \\
\mathrm{CCN} \\
\text { applicati } \\
\text { with p } \\
\text { adjustme } \\
2 \text { optimi } \\
\text { infe } \\
1 \text { pericarc } \\
1 \text { inapprc } \\
\mathrm{fi}\end{array}$ & $\begin{array}{l}\text { gements } \\
\text { f "chest } \\
\text { during } \\
\text { nal } \\
\text { esolved } \\
\text { neter } \\
\text { f signals } \\
\text { pocket } \\
\text { ns } \\
\text { effusion } \\
\text { ate ICD }\end{array}$ & $\begin{array}{r}3 \text { Lead disl } \\
5 \text { Device poc } \\
2 \text { Pericard } \\
4 \text { Bleedings }\end{array}$ & $\begin{array}{l}\text { dgements } \\
\text { et infections } \\
\text { l effusion } \\
\text { t CCM site }\end{array}$ & $\begin{array}{r}3 \text { Lead } \\
6 \mathrm{RV} \\
\text { Dislod } \\
6 \mathrm{RA} \\
\text { dislod } \\
3 \mathrm{CCM} \\
\text { dehiscen } \\
2 \mathrm{CCM} \\
\text { infec } \\
2 \mathrm{CCM} \\
\text { stimu } \\
1 \mathrm{CCM} \\
\text { blee } \\
2 \text { Lead pe } \\
2 \text { Sensati } \\
\mathrm{CC} \\
1 \text { Extra } \\
\text { stimu }\end{array}$ & $\begin{array}{l}\text { cture } \\
\text { ead } \\
\text { ment } \\
\text { ad } \\
\text { nent } \\
\text { ocket } \\
\text { erosion } \\
\text { ocket } \\
\text { on } \\
\text { ocket } \\
\text { ion } \\
\text { ocket } \\
\text { ig } \\
\text { oration } \\
\text { due to } \\
\text { I diac } \\
\text { ion }\end{array}$ & $\begin{array}{r}5 \text { lead disl } \\
1 \text { Generat } \\
\text { requirin } \\
\text { revision } \\
\text { replac }\end{array}$ & $\begin{array}{l}\text { gements } \\
\text { Erosion } \\
\text { ocket } \\
\text { d lead } \\
\text { ent }\end{array}$ \\
\hline
\end{tabular}

CCM: cardiac contractility modulation, OMT: optimal medical therapy, VF: ventricular fibrillation, VT: ventricular tachycardia, AF: atrial fibrillation, SVT: supraventricular tachycardia, HF: heart failure, and DVT: deep vein thrombosis.

* Due to either T-wave oversensing or the need for ICD lead repositioning.

studies were comparable between CCM and non-CCM groups. A quality assessment and publication bias analysis was completed and can be found in the supplemental material (available here).

\subsection{Outcome Measures}

3.2.1. Adverse Events and Total Mortality. The adverse events of each trial are detailed in Table 2. There was no significant difference between those receiving CCM + OMT intervention when compared to those receiving OMT alone with regard to worsening $\mathrm{HF} / \mathrm{HF}$ hospitalizations (OR 0.76, 95\% CI $0.53-1.08, \mathrm{p}=0.12$, Figure 4 ), arrhythmic events (OR $1.40,95 \%$ CI 0.89 to $2.22, \mathrm{p}=0.14$, Figure 5), pacemaker/ICD malfunction/sensing defect (OR 2.23, 95\% CI 0.97 to $5.15, \mathrm{p}$ $=0.06$, Figure 6 ), total hospitalizations (OR 0.73, 95\% CI 0.39 to $1.38, \mathrm{p}=0.33$, Figure 3 ), and total mortality (OR 1.04, 95\% CI 0.47 to $2.31, \mathrm{p}=0.92$, Figure 2 ). We were unable to assess difference in cardiac vs noncardiac mortality as cause of death was not specified for a majority of patients. Furthermore, it was not clear whether all the arrhythmias reported were symptomatic or required any particular intervention. 


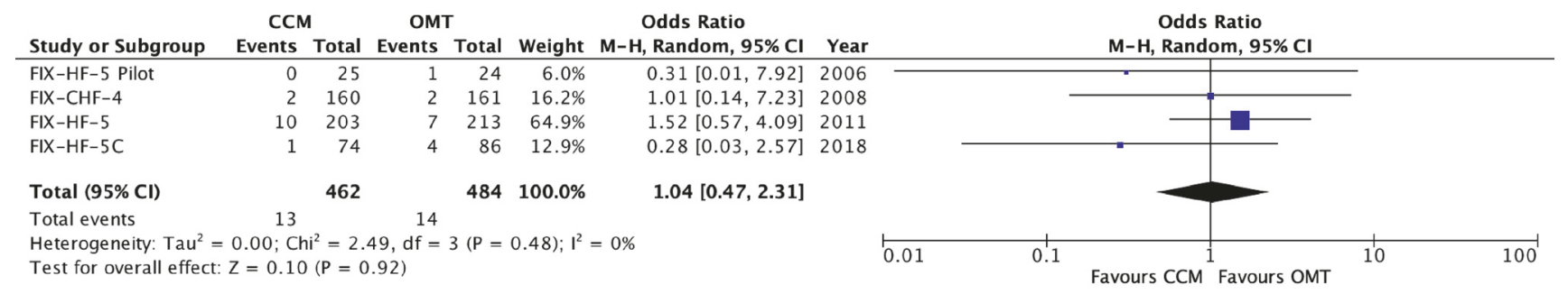

FIGURE 2: Forest plot of all-cause mortality (postrandomization/device implantation). A forest plot of the data available to us from the 4 RCTs assessing all-cause mortality in those with CCM compared to those with OMT alone. There was a nonsignificant difference in the rate of total hospitalizations between the two groups.

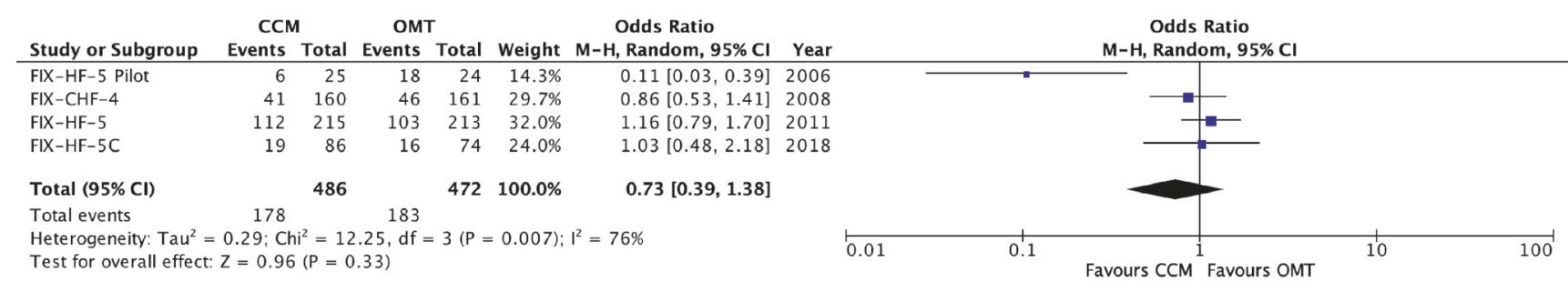

FIGURE 3: Forest plot of total hospitalizations in the CCM groups versus the control groups. A forest plot of the data available to us from the 4 RCTs assessing total hospitalizations in those with CCM compared to those with OMT alone. There was a nonsignificant difference in the rate of total hospitalizations between the two groups.

\begin{tabular}{|c|c|c|c|c|c|c|c|c|c|c|}
\hline Study or Subgroup & \multicolumn{2}{|l|}{ CCM } & ОМт & T Total & \multicolumn{2}{|r|}{ Odds Ratio } & Year & \multicolumn{2}{|c|}{$\begin{array}{c}\text { Odds Ratio } \\
\text { M-H, Random, } 95 \% \mathrm{Cl}\end{array}$} & \\
\hline FIX-HF-5 Pilot & 2 & 25 & 3 & 24 & $3.5 \%$ & $0.61[0.09,4.01]$ & 2006 & & & \\
\hline $\mathrm{FIX}-\mathrm{CHF}-4$ & 7 & 160 & 8 & 161 & $11.4 \%$ & $0.88[0.31,2.47]$ & 2008 & & & \\
\hline $\mathrm{FIX}-\mathrm{HF}-5$ & 72 & 210 & 85 & 212 & $78.7 \%$ & $0.78[0.52,1.16]$ & 2011 & - & - & \\
\hline $\mathrm{FIX}-\mathrm{HF}-5 \mathrm{C}$ & 3 & 74 & 7 & 86 & $6.4 \%$ & $0.48[0.12,1.91]$ & 2018 & & & \\
\hline Total $(95 \% \mathrm{Cl})$ & & 469 & & 483 & $100.0 \%$ & $0.76[0.53,1.08]$ & & & & \\
\hline Total events & 84 & & 103 & & & & & & & \\
\hline $\begin{array}{l}\text { Heterogeneity: } \mathrm{Tau}^{2} \\
\text { Test for overall effect }\end{array}$ & $\begin{array}{l}0.00 ; C h i \\
z=1.54\end{array}$ & $\begin{array}{l}\mathrm{i}^{2}=0 . \\
(\mathrm{P}=0\end{array}$ & $\begin{array}{l}57, \mathrm{df}= \\
.12)\end{array}$ & $3(P=C$ & $0.90) ; 1^{2}=$ & $=0 \%$ & 0.01 & Favours $\mathrm{CCM}^{1}$ & Favours OMT & 100 \\
\hline
\end{tabular}

FIGURE 4: Forest plot of worsening HF/HF-related hospitalizations in the CCM groups versus the control groups. A forest plot of the data available to us from the 4 RCTs assessing worsening HF and HF-related hospitalizations in those with CCM compared to those with OMT alone. There was a nonsignificant trend in reduced HF hospitalizations in those with CCM.

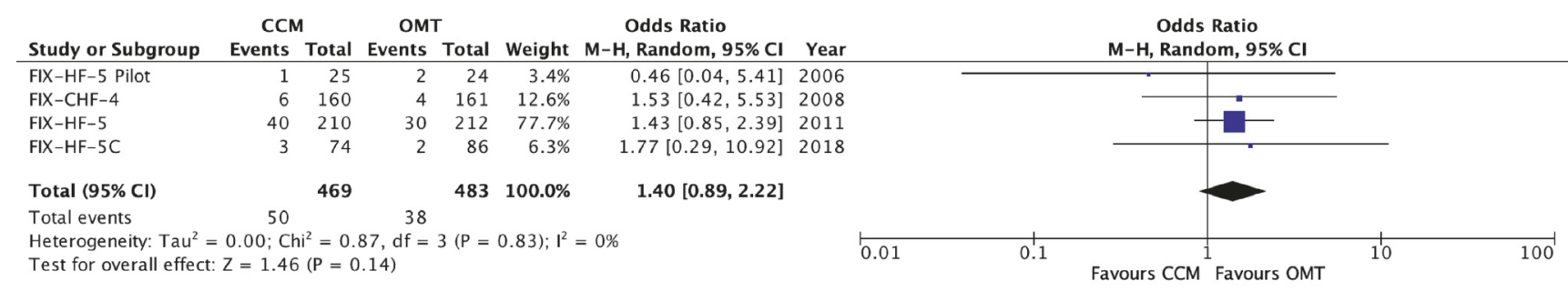

FIGURE 5: Forest plot of cardiac arrhythmias in CCM groups versus the control groups. A forest plot of the data available to us from the 4 RCTs assessing arrhythmias in those with CCM compared to those with OMT alone. There was a nonsignificant trend in reduced arrhythmic events favoring the OMT group.

3.2.2. Peak $\mathrm{VO}_{2}$. Evaluating the peak $\mathrm{VO}_{2}$ response was limited by the variation in data reporting among the four randomized controlled trials and we were not able to perform analysis on the pooled data due to that. Overall, the mean difference of peak $\mathrm{VO}_{2}$ favored the CCM group in all studies. The FIX-HF-5 pilot study reported an overall mean difference of $0.2 \mathrm{~mL} \mathrm{O}_{2} / \mathrm{kg} / \mathrm{min}$ favoring the treatment group, although this was not statistically significant [12]. The FIX-CHF-4 study also reported positive findings of $0.52 \mathrm{~mL} \mathrm{O}_{2} / \mathrm{kg} / \mathrm{min}$ in the treatment group relative the sham therapy. [13]. The FIXHF-5 study by Kadish et al. reported improvement of 0.65 $\mathrm{mL} \mathrm{O}_{2} / \mathrm{kg} / \mathrm{min}$ [20]. Lastly, the most recent FIX-HF-5C study demonstrated improvement in $\mathrm{VO}_{2}$ of $0.84 \mathrm{~mL} \mathrm{O} / \mathrm{kg} / \mathrm{min}$ [21]. All of the latter trials reached statistical significance. 


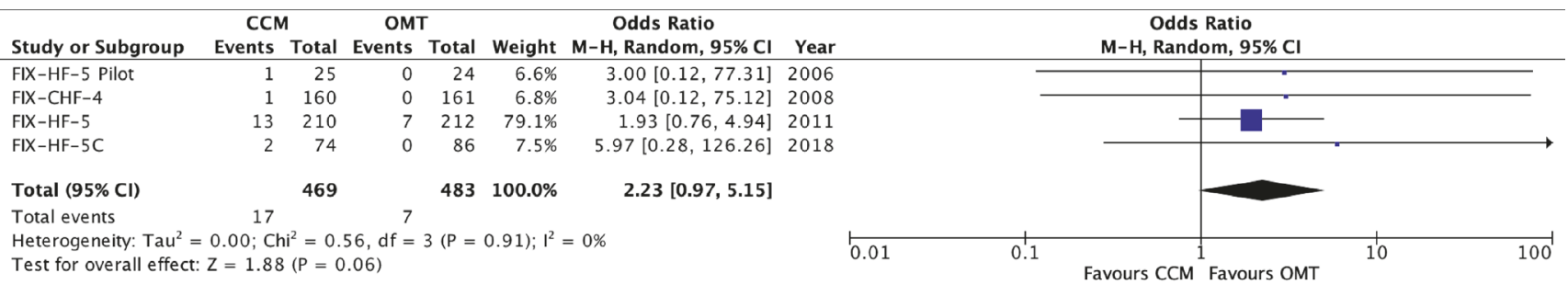

FIGURE 6: Forest plot of pacemaker/ICD sensing defects/malfunction in CCM groups versus the control groups. A forest plot of the data available to us from the 4 RCTs assessing pacemaker/ICD sensing defects/malfunction in those with CCM compared to those with OMT alone. There was a nonsignificant trend in increased sensing defect and malfunction in the CCM group.

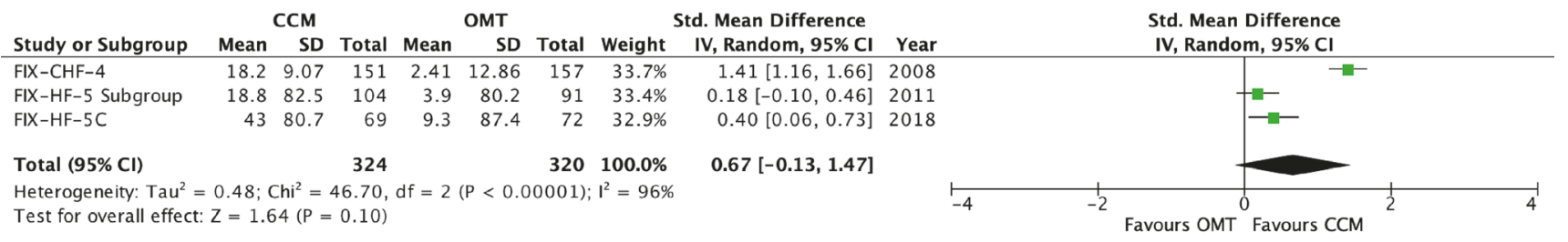

FIGURE 7: Forest plot of the six-minute walking distance in the CCM groups versus the control groups. A forest plot of the data available to us from the 4 RCTs assessing 6MWD in those with CCM compared to those with OMT alone. There was no statistically significant difference in 6MWD between these two groups.

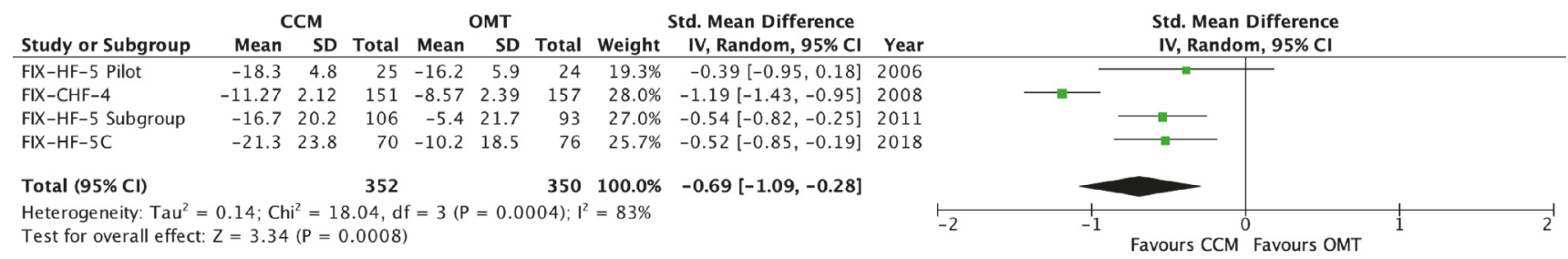

FIGURE 8: Forest plot of the MLWHFQ in the CCM groups versus the control groups. A forest plot of the data available to us from the 4 RCTs assessing MLWHFQ in those with CCM compared to those with OMT alone. There was a statistically significant difference between these two groups favoring CCM.

3.2.3. Six-Minute Walking Distance. There was no significant difference in the 6MWD in the CCM group compared to those receiving OMT alone (SMD 0.67-meters, 95\% CI - 0.13 to $1.47, \mathrm{p}=0.10$, Figure 7 ). In the FIX-HF-5 pilot study there was a nonsignificant increase in the $6 \mathrm{MWD}$ in the CCM group at 24 weeks [12]. Individual data from this study was not available for inclusion in our analysis. In the FIX-HF5 , it is important to note that, for all comers, they found a nonsignificant improvement in the 6MWD in the CCM group $(\sim 10 \mathrm{~m})$. The only data available for inclusion into our analysis was that of the "responders" subgroup (LVEF $\geq$ $25 \%$ and $\leq 45 \%$ ) of FIX-HF-5 and FIX-HF-5C, as shown in Figure $2[20,21]$.

3.2.4. Quality of Life Measured by MLHFQ. Significant improvement in quality of life in those receiving CCM intervention was noted based on the decrease in MLWHFQ score (SMD $-0.69,95 \%$ CI -1.09 to $-0.28, \mathrm{p}<0.01$, Figure 8 ). In the FIX-HF-5 study CCM therapy improved the MLWHFQ for the total cohort, and again only the same subgroup was available for our statistical analysis $[20,21]$

\section{Discussion}

Several studies suggest cardiac contractility modulation might be a promising therapy for systolic heart failure patients with narrow QRS who are already on OMT. CCM therapy enhances LV contractility independent of myocardial synchrony and QRS duration by delivering signals 30-40 msec after activation of myocytes during the absolute refractory period [20, 23-25]. These signals are nonexcitatory and therefore should not initiate contraction or modify myocyte activation $[7,12]$. It is believed these signals help in regulating calcium cycling by cardiac myocytes through phosphorylation of proteins and expression of genes involved in this process. The modulation of calcium entry into myocytes during the refractory period is thought to lead to augmented contractility $[7,26,27]$. For these reasons, CCM may play 
an important role in managing patients in a subset of heart failure with reduced ejection fraction.

Our meta-analysis included four randomized clinical trials with a total of 801 enrolled patients comparing CCM therapy versus OMT. The objective outcome of peak $\mathrm{VO}_{2}$ was reported in different ways in the four studies; however, the mean difference of peak $\mathrm{VO}_{2}$ favored the CCM group in all studies. Overall, we found that CCM therapy improves QOL measured by MLWHFQ when compared to optimal medical management alone and trend towards improving the $6 \mathrm{MWD}(\mathrm{p}=0.10)$. In the most recent RCT by Abraham et al. peak $\mathrm{VO}_{2}, \mathrm{MLWHFQ}$, NYHA functional class, and 6MWD were all better in the CCM treatment versus control group [21]. The study included a total of 160 patients with NYHA functional class III or IV symptoms, QRS duration $<130 \mathrm{msec}$, and ejection fraction $\geq 25 \%$ and $\leq 45 \%$ patients. The improvements seen were less than achieved with previous CRT trials $[2,28,29]$. A recent meta-analysis for the individual patient's data of the three prior RCTs suggested modest beneficial role of CCM in improving exercise capacity and quality of life. [30]. This analysis included only three randomized controlled trials and did not address worsening heart failure/hospitalizations, incidence of cardiac arrhythmias, pacemaker/ICD malfunctioning/missensing, all-cause hospitalizations, or all-cause mortality. Certain groups experienced more robust improvements in 6MWD in that metaanalysis. These groups included those of male gender, those with ischemic cardiomyopathy, and those with an EF between $25-45 \%$ [30].

In the FIX-HF-5 pilot study, there was a nonsignificant improvement in the 6MWD between the intervention group and the control group [12]. Similarly, in the FIX-HF-5 study by Kadish et al. there was a 10-meter improvement in the 6MWD in the CCM group when compared to the control group which was not statistically significant [20]. It is important to point out that we were only able to include the "responders" subgroup of patients from Kadish et al. study in our 6MWD and MLWHFQ statistical analysis as this population was identified as better responders to CCM therapy $[20,21]$. In our study, the improvements seen in the MLWHFQ may well be significant statistically given the more robust sample size included in this analysis. This is less likely to be clinically relevant given the minimal improvement and potential for placebo effects in some of the included studies. Similarly, the trend of 0.67 -meter improvement noted in $6 \mathrm{MWD}$ is likely far from relevance in light of risks associated with device placement.

The FIX-HF-5 pilot study found no difference in QOL using the MLWHFQ due to similar improvements in the MLWHFQ between both groups (CCM on and CCM off). This raised the suspicion that the benefits of CCM may be related to placebo effect [22]. However, parameters such as $\mathrm{pVO}_{2}$ provide objective evidence of improved functional capacity overall improved in the 4 studies.

In our meta-analysis we found trend towards lower rates of worsening HF ( $\mathrm{p}=0.12)$; however, we also identified a trend towards increased arrhythmic events $(p=0.14)$. Total hospitalization and mortality were similar in the two treatment groups in our study. An earlier meta-analysis of 3 randomized studies concluded that CCM was not associated with a worse prognosis when compared to OMT [31]. The FIX-HF-5 pilot study showed significantly reduced all-cause hospitalizations for the CCM group when compared with OMT alone (84\% versus 62\%, respectively) despite the CCM population having worse baseline characteristics [12]. However, these results were not reproducible in the subsequent two trials which revealed no statistically significant difference in hospitalization rates alone $[13,20,21]$. The primary safety end point of the study, which was a noninferiority assessment of the composite of all-cause mortality and all-cause hospitalization, was satisfied in the FIX-HF-5 study [20]. In FIXHF 5C, CCM led to significant improvement in the combined end points of survival free of cardiac death and heart failure hospitalizations [21].

Interestingly, in our study we found that sensing defects may be an issue in those receiving CCM despite the routine evaluation for oversensing in patients with ICDs during CCM implantation ( $p=0.06$ ) [9]. About $80 \%$ of the cohort in our meta-analysis already had implantable devices (ICD or pacemaker). Implantation of another device and lead system may predispose to an increase in complication rates (Table 2) such as leads dislodgment, pericardial effusion, DVT, lead fracture, perforation, pocket infection, and need for extraction. Device complications are important to ascertain as they may lead to increased hospitalizations and even mortality irrespective of the underlying $\mathrm{CHF}$. The primary safety endpoint for FIX-HF-5C study was defined as the proportion of subjects who did not experience either an Optimizer device-related complication or a procedure-related complication by 24 weeks and was met in that study $(89.7 \%$ complication-free rate) [21].

Importantly, all studies were limited by short follow-up periods which preclude the assessment of any long-term benefit. CCM may become the device therapy of choice in patients with systolic HF and narrow QRS based on symptomatic improvement and reducing $\mathrm{HF}$ admissions. However, the clinical benefits will be limited if no improvement in total mortality and/or total hospitalizations is achieved.

Several studies of longer follow-up assessing mortality following CCM placement have shown promising outcomes [32-36]. The longest follow-up among these studies was by Liu et at with 6 years of follow-up of 41 patients demonstrating significant improvement in mortality and heart failure hospitalization in the CCM group for patients with EF $\geq$ 25-40\% [34]. Similar studies enrolling 81 patients followed for 3 years and another enrolling 68 patients followed for 5 eyars also demonstrated better than expected mortality rates $[33,36]$. The first of these studies, a retrospective analysis of 54 consecutive patients receiving CCM with 3 years of followup, revealed an all-cause mortality similar to that predicted by the Seattle Heart Failure Model (SHFM) [32]. The most recent study included retrospective review of 140 patients in the CCM registry divided patients into those with an EF 25-45\%, EF 24-34\% and an EF 35-45\%. This study revealed mortality similar to that predicted by the SHFM in all comers (i.e., EF 25-45\%) and in those with an EF between 24-34\%. They reported a significant improvement in 3-year mortality compared to expected in the 57 patients with an EF between 
35 and $45 \%$ ( $88 \%$ vs $74.7 \%$ ) [35]. A powered large randomized control trial with long-term follow-up which is needed to address such important outcomes will be different.

Adverse events and procedure complications are currently under evaluation by two ongoing studies: Continued Access Protocol for the Evaluation of the OPTIMIZER Smart System (FIX-HF-5CA) is evaluating the serious adverse device Events in 250 participants and Evaluation of the Safety and Efficacy of the 2-lead OPTIMIZER ${ }^{\circledR}$ Smart System (FIX$\mathrm{HF}-5 \mathrm{C} 2$ ) is evaluating optimizer device- or procedure-related complication in 60 participants. The recently published study by Anker et al. revealed two severe ICD related adverse events and ten severe adverse events related to arrhythmias [35]. With the technological advancements, the potential to merge ICD or CRT and CCM devices is feasible and might reduce the risk of the procedure and the device-related complications.

\section{Future Direction of CCM Therapy}

We feel that the future direction of CCM is to conduct randomized controlled trials with long follow-up to evaluate heart failure and total hospitalizations and death. Furthermore, objective data such as the impact of CCM on left ventricular end systolic and diastolic diameter and ejection fraction need to be evaluated. Lastly, integration of CCM technology into the current implanted cardiac devices will hopefully significantly reduce the complications due to additional device and procedure.

\section{Limitations}

The meta-analysis is based on study level data since patient level data was largely unavailable. Variations in study design are noted in Table 1 . Sources of bias within these studies include lack of blinding as well as lack of sham procedure in some studies. Patients with atrial arrhythmias and atrial fibrillation were excluded but current studies suggest that CCM could be feasible in those with permanent atrial fibrillation [10]. The short follow-up duration precludes accurate assessment of benefits in hard clinical outcomes.

\section{Conclusion}

Our meta-analysis demonstrates that short-term treatment with CCM improves QOL measured by MLFHQ. The clinical relevance of this improvement might be insignificant. Trend towards higher incidence of pacemaker/ICD device malfunction was noted in the CCM group when compared to those receiving optimal medical therapy alone. We found no difference with regard to $6 \mathrm{MWD}$, arrhythmic events, HF hospitalizations, total hospitalizations, and mortality between the two groups. The Food and Drug Administration (FDA) recently issued memorandum addressing CCM as a breakthrough designated device that might help patient population with limited additional therapy options that can improve heart failure symptoms and hospital admission and survival. Due to the better outcome with longer follow-up and less severe LV dysfunction, larger randomized controlled trials with a longer follow-up periods are needed to determine whether CCM should be widely accepted or not as a therapeutic option for patients with advanced, narrow QRS complex systolic HF or for those who did not experience symptomatic improvement from CRT.

\section{Data Availability}

This is a meta-analysis of randomized controlled trials. All the data used are included within this manuscript.

\section{Additional Points}

Brief Summary. Cardiac contractility modulation (CCM) is a novel therapy that targets patients with a limited device therapy options for symptomatic improvement and reducing heart failure admissions. More data are available now and with promising results. We hope to condense the studies into a concise systematic review and meta-analysis of the 4 major RCT. We would also like to focus on highlighting the efficacy, safety, and potential adverse effects of CCM in our study.

\section{Disclosure}

An earlier version of this abstract was presented at AHA National in 2018. Dr. Maskoun has received research grants from Medtronic.

\section{Conflicts of Interest}

The authors declare that they have no conflicts of interest.

\section{Acknowledgments}

All other authors have reported that they have no relationships relevant to the contexts of this paper to disclose.

\section{Supplementary Materials}

Supplemental Table 1: risk of bias of the individual studies by Cochrane Risk Assessment Tool. (Supplementary Materials)

\section{References}

[1] M. R. Bristow, L. A. Saxon, J. Boehmer et al., "Cardiac-resynchronization therapy with or without an implantable defibrillator in advanced chronic heart failure," The New England Journal of Medicine, vol. 350, no. 21, pp. 2140-2150, 2004.

[2] W. T. Abraham, W. G. Fisher, A. L. Smith et al., "Cardiac resynchronization in chronic heart failure," The New England Journal of Medicine, vol. 346, no. 24, pp. 1845-1853, 2002.

[3] A. E. Epstein, J. P. Dimarco, K. A. Ellenbogen et al., "2012 ACCF/AHA/HRS focused update incorporated into the ACCF/AHA/HRS 2008 guidelines for device-based therapy of cardiac rhythm abnormalities: a report of the American college of cardiology foundation/American heart association task force on practice guidelines and the heart rhythm society," Journal of 
the American College of Cardiology, vol. 61, no. 3, pp. e6-e75, 2013.

[4] H. J. Shenkman, V. Pampati, A. K. Khandelwal et al., "Congestive heart failure and QRS duration: establishing prognosis study," Chest, vol. 122, no. 2, pp. 528-534, 2002.

[5] J. M. Aranda, G. W. Woo, R. S. Schofield et al., "Management of heart failure after cardiac resynchronization therapy: integrating advanced heart failure treatment with optimal device function," Journal of the American College of Cardiology, vol. 46, no. 12, pp. 2193-2198, 2005.

[6] J. F. Beshai, R. A. Grimm, S. F. Nagueh et al., "Cardiacresynchronization therapy in heart failure with narrow QRS complexes," The New England Journal of Medicine, vol. 357, no. 24, pp. 2461-2471, 2007.

[7] C. B. Brunckhorst, I. Shemer, Y. Mika, S. A. Ben-Haim, and D. Burkhoff, "Cardiac contractility modulation by non-excitatory currents: Studies in isolated cardiac muscle," European Journal of Heart Failure, vol. 8, no. 1, pp. 7-15, 2006.

[8] R. Kahwash, D. Burkhoff, and W. T. Abraham, "Cardiac contractility modulation in patients with advanced heart failure," Expert Review of Cardiovascular Therapy, vol. 11, no. 5, pp. 635645, 2013.

[9] F. Abi-Samra and D. Gutterman, "Cardiac contractility modulation: a novel approach for the treatment of heart failure," Heart Failure Reviews, vol. 21, no. 6, pp. 645-660, 2016.

[10] S. Röger, R. Schneider, B. Rudic et al., "Cardiac contractility modulation: First experience in heart failure patients with reduced ejection fraction and permanent atrial fibrillation," Europace, vol. 16, no. 8, pp. 1205-1209, 2014.

[11] H. Nägele, S. Behrens, and C. Eisermann, "Cardiac contractility modulation in non-responders to cardiac resynchronization therapy," Europace, vol. 10, no. 12, pp. 1375-1380, 2008.

[12] S. B. Neelagaru, J. E. Sanchez, S. K. Lau et al., "Nonexcitatory, cardiac contractility modulation electrical impulses: Feasibility study for advanced heart failure in patients with normal QRS duration," Heart Rhythm, vol. 3, no. 10, pp. 1140-1147, 2006.

[13] M. Borggrefe, T. Lawo, C. Butter et al., "Randomized, double blind study of non-excitatory, cardiac contractility modulation electrical impulses for symptomatic heart failure," European Journal of Heart Failure Supplements, vol. 29, no. 8, pp. 10191028, 2008.

[14] D. Moher, L. Shamseer, M. Clarke et al., "Preferred reporting items for systematic review and meta-analysis protocols (PRISMA-P) 2015 statement," Systematic Reviews, vol. 4, no. 1, article 1, 2015.

[15] D. P. Francis, W. Shamim, L. C. Davies et al., "Cardiopulmonary exercise testing for prognosis in chronic heart failure: continuous and independent prognostic value from VE/VCO2 slope and peak VO2," European Heart Journal, vol. 21, no. 2, pp. 154$161,2000$.

[16] D. M. Mancini, H. Eisen, W. Kussmaul, R. Mull, L. H. Edmonds Jr., and J. R. Wilson, "Value of peak exercise oxygen consumption for optimal timing of cardiac transplantation in ambulatory patients with heart failure," Circulation, vol. 83 , no. 3, pp. 778786, 1991.

[17] P. A. McElroy, J. S. Janicki, and K. T. Weber, "Cardiopulmonary exercise testing in congestive heart failure," American Journal of Cardiology, vol. 62, no. 2, pp. 35a-40a, 1988.

[18] C. Demers, R. S. McKelvie, A. Negassa, and S. Yusuf, "Reliability, validity, and responsiveness of the six-minute walk test in patients with heart failure," American Heart Journal, vol. 142, no. 4, pp. 698-703, 2001.
[19] T. S. Rector, S. H. Kubo, and J. N. Cohn, "Validity of the minnesota living with heart failure questionnaire as a measure of therapeutic response to enalapril or placebo," American Journal of Cardiology, vol. 71, no. 12, pp. 1106-1107, 1993.

[20] A. Kadish, K. Nademanee, K. Volosin et al., "A randomized controlled trial evaluating the safety and efficacy of cardiac contractility modulation in advanced heart failure," American Heart Journal, vol. 161, no. 2, pp. 329-337.e2, 2011.

[21] W. T. Abraham, K. Kuck, R. L. Goldsmith et al., "A randomized controlled trial to evaluate the safety and efficacy of cardiac contractility modulation," JACC: Heart Failure, vol. 6, no. 10, pp. 874-883, 2018.

[22] J. P. T. Higgins and S. E. Green, Cochrane Handbook for Systematic Reviews of Interventions Version 5.1.0, 2011, http://www .cochrane-handbook.org.

[23] T. Lawo, M. Borggrefe, C. Butter et al., "Electrical signals applied during the absolute refractory period: an investigational treatment for advanced heart failure in patients with normal QRS duration," Journal of the American College of Cardiology, vol. 46, no. 12, pp. 2229-2236, 2005.

[24] D. Burkhoff, I. Shemer, B. Felzen et al., "Electric currents applied during the refractory period can modulate cardiac contractility in vitro and in vivo," Heart Failure Reviews, vol. 6, no. 1, pp. 2734, 2001.

[25] C.-M. Yu, J. Y.-S. Chan, Q. Zhang et al., "Impact of cardiac contractility modulation on left ventricular global and regional function and remodeling," JACC: Cardiovascular Imaging, vol. 2, no. 12, pp. 1341-1349, 2009.

[26] E. H. Wood, R. L. Heppner, and S. Weidmann, "Inotropic effects of electric currents. I. Positive and negative effects of constant electric currents or current pulses applied during cardiac action potentials. II. Hypotheses: calcium movements, excitation-contraction coupling and inotropic effects.," Circulation Research, vol. 24, no. 3, pp. 409-445, 1969.

[27] R. L. Kaufmann, H. Antoni, R. Hennekes, R. Jacob, M. Kohlhardt, and M. J. Lab, "Mechanical response of the mammalian myocardium to modifications of the action potential," Cardiovascular Research, vol. 5, supplement 1, no. 1, pp. 64-70, 1971.

[28] J. B. Young, W. T. Abraham, A. L. Smith et al., "Combined cardiac resynchronization and implantable cardioversion defibrillation in advanced chronic heart failure: the MIRACLE ICD Trial," Journal of the American Medical Association, vol. 289, no. 20, pp. 2685-2694, 2003.

[29] G. L. Botto and G. Russo, "Effect of cardiac resynchronization therapy on quality of life: The best gets the least," Europace, vol. 14, no. 11, pp. 1537-1539, 2012.

[30] F. Giallauria, C. Vigorito, M. F. Piepoli, and A. J. Stewart Coats, "Effects of cardiac contractility modulation by nonexcitatory electrical stimulation on exercise capacity and quality of life: An individual patient's data meta-analysis of randomized controlled trials," International Journal of Cardiology, vol. 175, no. 2, pp. 352-357, 2014.

[31] J. S. W. Kwong, J. E. Sanderson, and C.-M. Yu, "Cardiac contractility modulation for heart failure: A meta-analysis of randomized controlled trials," Pacing and Clinical Electrophysiology, vol. 35, no. 9, pp. 1111-1118, 2012.

[32] T. Schau, M. Seifert, J. Meyhfer, M. Neuss, and C. Butter, "Longterm outcome of cardiac contractility modulation in patients with severe congestive heart failure," Europace, vol. 13, no. 10, pp. 1436-1444, 2011. 
[33] J. Kuschyk, S. Roeger, R. Schneider et al., "Efficacy and survival in patients with cardiac contractility modulation: Long-term single center experience in 81 patients," International Journal of Cardiology, vol. 183, Article ID 19592, pp. 76-81, 2015.

[34] M. Liu, F. Fang, X. X. Luo et al., "Improvement of longterm survival by cardiac contractility modulation in heart failure patients: a case-control study," International Journal of Cardiology, vol. 206, pp. 122-126, 2016.

[35] S. D. Anker, M. Borggrefe, H. Neuser et al., "Cardiac contractility modulation improves long-term survival and hospitalizations in heart failure with reduced ejection fraction," European Journal of Heart Failure, 2019.

[36] A. Kloppe, T. Lawo, D. Mijic, F. Schiedat, A. Muegge, and B. Lemke, "Long-term survival with cardiac contractility modulation in patients with NYHA II or III symptoms and normal QRS duration," International Journal of Cardiology, vol. 209, pp. 291-295, 2016. 


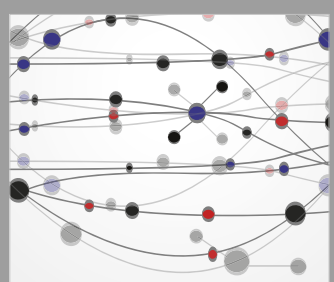

The Scientific World Journal
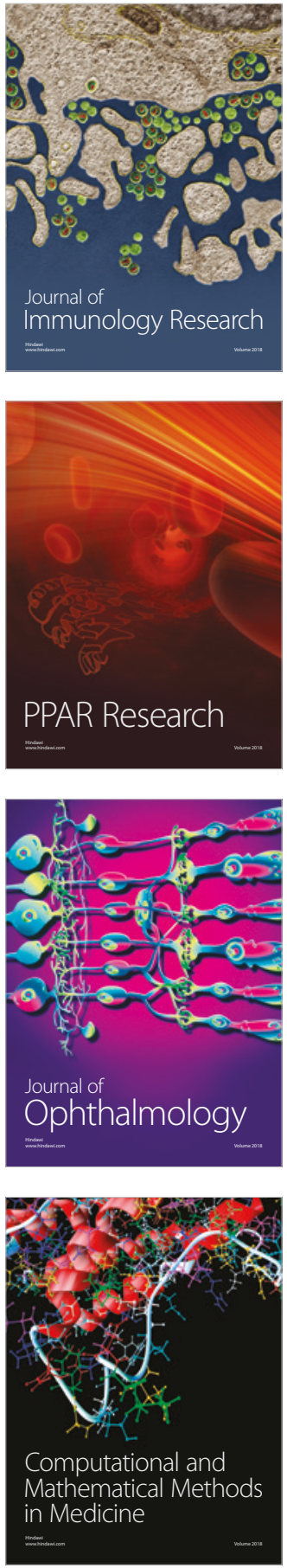

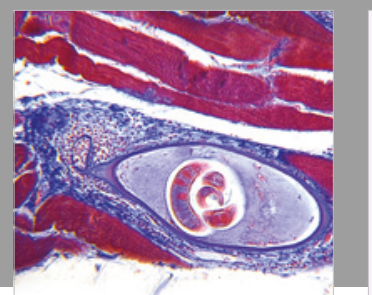

Gastroenterology Research and Practice

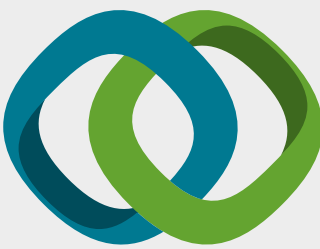

\section{Hindawi}

Submit your manuscripts at

www.hindawi.com
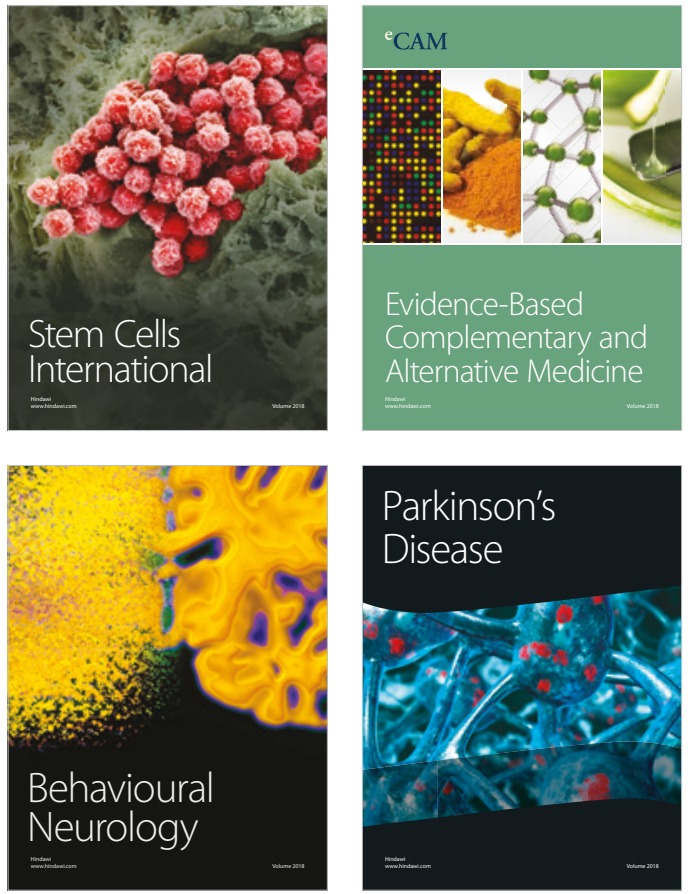

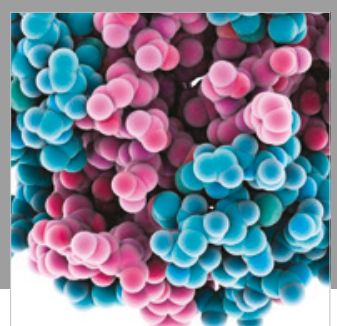

ournal of

Diabetes Research

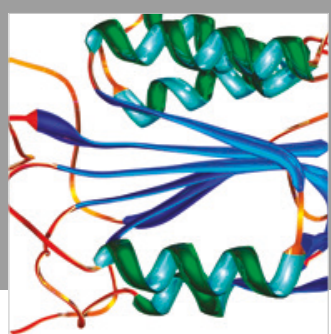

Disease Markers
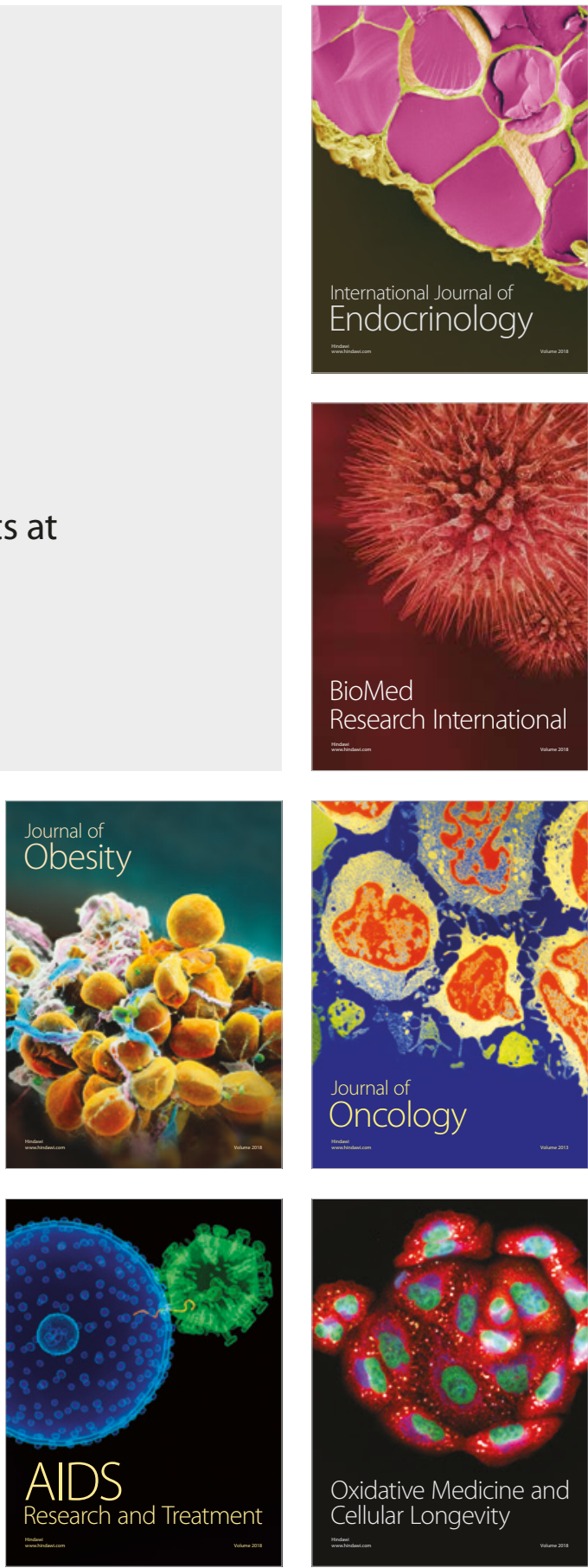